\title{
Optimum reaction time, performance and exhaust emissions of biodiesel produced by microwave irradiation
}

\author{
${ }^{1} * A$. A. Refaat; ${ }^{1}$ S. T. El Sheltawy; ${ }^{2}$ K. U. Sadek \\ ${ }^{I}$ Department of Chemical Engineering, Faculty of Engineering, Cairo University, Cairo, Egypt \\ ${ }^{2}$ Department of Organic Chemistry, Faculty of Science, Menia University, Cairo, Egypt \\ Received 16 February 2008; revised 2 March 2008; accepted 2 April 2008; available online 1 June 2008
}

\begin{abstract}
While transesterification is well established, there remain considerable inefficiencies in existing transesterification processes. In this study an alternative energy stimulant, "microwave irradiation" was used for the production of the alternative energy source, biodiesel. The optimum parametric conditions obtained from the conventional technique were applied using microwave irradiation in order to compare both systems. The results showed that application of radio frequency microwave energy offers a fast, easy route to this valuable biofuel with advantages of enhancing the reaction rate and improving the separation process. The methodology allows for the use of high free fatty acid content feedstock, including used cooking oil; hence it helps to reduce the cost of production which constitutes a major hurdle towards widespread commercialization of biodiesel. The study also showed that the optimum reaction time for microwave-enhanced biodiesel production should be highly respected. Exceeding the optimum reaction time will lead to deterioration of both biodiesel yield and purity. This paper also reported the performance and exhaust emissions from a diesel engine when fuelled with a petroleum diesel fuel and two different biodiesel fuels; one obtained by the conventional technique and the other by microwave irradiation. It was concluded that microwave-enhanced biodiesel is not, at least, inferior to that produced by the conventional technique.
\end{abstract}

Key words: Transesterification, engine performance, exhaust emissions, vegetable oil

\section{INTRODUCTION}

The three basic methods of ester production from oils/fats are the base-catalyzed transesterification, the acid-catalyzed esterification, and enzymatic catalysis. The most commonly used method of which is the basecatalyzed transesterification technique as it is the most economical process (Singh et al., 2006). The transesterification reaction is an equilibrium and the transformation occurs essentially by mixing the reactants. However, the presence of a catalyst accelerates considerably the adjustment of the equilibrium (Ma and Hanna, 1999). Methanolysis with $1 \%$ wt. potassium hydroxide catalyst resulted in successful conversion giving the best yields and viscosities of the esters (Refaat et al., 2008). The stoichiometric reaction requires $1 \mathrm{~mol}$ of a triglyceride and $3 \mathrm{~mol}$ of the alcohol. However, an excess of the alcohol is used to increase the yields of the alkyl esters and to allow its phase separation from the glycerol formed (Schuchardt et al., 1998). The optimum methanol/oil molar ratio was found to be 6:1 (Refaat $e t$

X $*$ Corresponding Author Email: aarefaat@hotmail.com Tel./Fax: +20 122277897 al., 2008). While transesterification is well-established, and becoming increasingly important, there remains considerable inefficiencies in existing transesterification processes. In conventional heating of transesterification process (batch, continuous, and supercritical methanol process), heat energy is transferred to the raw material through convection, conduction, and radiation from surfaces of the raw material. Thus, the conventional heating consumes more energy and take long preheat and reaction time, optimally $1 \mathrm{~h}$. (Refaat et al., 2008), to produce over 95 percent conversion yield biodiesel product.

An alternative energy stimulant, "microwave irradiation" can be used for the production of the alternative energy source, biodiesel. In the electromagnetic radiation spectrum, the microwave radiation region is located between infrared radiation and radio waves. Microwaves (MW) have wavelengths of $1 \mathrm{~mm}-1 \mathrm{~m}$, corresponding to frequencies between $0.3-300 \mathrm{GHz}$. In general, in order to avoid interference, industrial and domestic microwave apparatus are regulated to $12.2 \mathrm{~cm}$, 
corresponding to a frequency of $2.45 \mathrm{GHz}$, but other frequency allocations do exist (Lidstrom et al., 2001). Microwaves, a non-ionizing radiation incapable of breaking bonds, are a form of energy and not heat and are manifested as heat through their interaction with the medium or materials wherein they can be reflected (metals), transmitted (good insulators that will not heat) or absorbed (decreasing the available microwave energy and rapidly heating the sample) (Varma, 2001). Microwaves, representing a non-ionizing radiation, influence molecular motions such as ion migration or dipole rotations, but not altering the molecular structure. Polar solvents of low molecular weight and high dielectric constant irradiated by microwaves increase their temperature very rapidly, reaching boiling point in a short time: in this class of solvents the rate of a given reaction is more enhanced. Typical solvents widely employed in microwave chemistry are water, methanol, ethanol, and acetone. In the presence of microwaves, common solvents are found to boil at higher temperatures: for water the difference is about $5{ }^{\circ} \mathrm{C} ; 19^{\circ} \mathrm{C}$ for methanol, up to $36^{\circ} \mathrm{C}$ was the difference measured for tetrahydrofuran and acetonitrile. These differences were explained with the different mode of energy supply (Fini and Breccia, 1999). Microwave irradiation, an unconventional energy source, has been used for a variety of applications including organic synthesis, wherein chemical reactions are accelerated because of selective absorption of MW energy by polar molecules, non-polar molecules being inert to the MW dielectric loss (Varma, 2001). The application of microwave irradiation in conjunction with the use of catalysts or mineral-supported reagents enables organic reactions to occur expeditiously at ambient pressure, thus providing unique chemical processes with special attributes such as enhanced reaction rates, higher yields, and the associated ease of manipulation. There are two mechanisms by which microwave energy can interact with a sample. If a molecule possesses a dipole moment, then, when it is exposed to microwave irradiation, the dipole tries to align with the applied electric field. Because the electric field is oscillating, the dipoles constantly try to realign to follow this. At $2.45 \mathrm{GHz}$, molecules have time to align with the electric field but not to follow the oscillating field exactly. This continual reorientation of the molecules results in friction and thus heat. If a molecule is charged, then the electric field component of the microwave irradiation moves the ions back and forth through the sample while also colliding them into each other. This movement again generates heat. Because the mixture of vegetable oil, methanol, and potassium hydroxide contains both polar and ionic components, rapid heating is observed upon microwave irradiation, and because the energy interacts with the sample on a molecular level, very efficient heating can be obtained. In addition, because the energy is interacting with the molecules at a very fast rate, the molecules do not have time to relax and the heat generated can be, for short times, much greater than the overall recorded temperature of the bulk reaction mixture. In essence, there will be instantaneous localized superheating. Thus, the bulk temperature may not be an accurate measure of the temperature at which the actual reaction is taking place (Barnard et al., 2007). Microwave heating compares very favorably over conventional methods, where heating can be relatively slow and inefficient because transferring energy into a sample depends upon convection currents and the thermal conductivity of the reaction mixture (Koopmans et al., 2006).

Successful alternative fuels should fulfill environmental and energy security needs without sacrificing operating performance. Operationally, biodiesel performs very similar to low sulfur diesel in terms of power, torque, and fuel without major modification of engines or infrastructure (Van Gerpen, 2005). Compared to petroleum diesel, the engine efficiency is not significantly affected by using biodiesel (Dorado et al., 2003b). However, an increase in fuel consumption is observed. This increase is proportional to the decrease in the heating value of biodiesel (Lapuerta et al., 2008). Brake specific energy consumption (bsec) or brake thermal efficiency (the inverse of bsec), are more adequate parameters than the break specific fuel consumption (bsfc) for comparing fuels and for evaluating the engine capability to be fuelled with biodiesel and biodiesel blends (Cardone et al., 2002). Combustion efficiency remained constant using either biodiesel or diesel fuel (Dorado et al., 2003a). Biodiesel possesses several distinct advantages over petro-diesel regarding exhaust emissions (Kegl, 2008) Compared to mineral diesel, biodiesel generally causes a decrease of unburned $\mathrm{HC}$, $\mathrm{CO}$ and $\mathrm{PM}$ emissions and an increase of $\mathrm{NO}_{\mathrm{x}}$ emission (Tat et al., 2007). The results indicate that, by using biodiesel, harmful emissions can be reduced to some extent by adjusting the injection pump timing properly 
(Kegl, 2006). This research was carried out in Cairo and Menia Universities in Egypt during the year 2007.

\section{MATERIALS AND METHODS}

The complete methodology of the conventional mixing technique was discussed in details in a previous study by the authors (Refaat et al., 2008) in which two different biodiesel fuels, obtained from waste cooking oils with different previous uses, were investigated and neat sunflower oil was used as a reference. The experiments have been run in triplicate; each set of operation conditions was conducted three times, once with neat sunflower oil used as a reference and twice with waste vegetable oils (WVOs) obtained from two different sources: one collected from a house (domestic waste vegetable oil-DWVO) and the other from a fastfood popular restaurant (Restaurant waste vegetable oil-RWVO). The used frying oil collected from the house (domestic waste vegetable oil-WVOD) was sunflower oil used for 3 times at a cooking temperature of $130^{\circ} \mathrm{C}$. The used frying oil collected from the fast-food popular restaurant (restaurant waste vegetable oil-WVOR) included sunflower, and canola feedstock. Information gathered from the participating restaurant, showed that the cooking temperature of the oils varied from $170^{\circ} \mathrm{C}$. The oils were kept at these temperatures for ten $h$. per day and were replaced three times per week.

Methyl, rather than ethyl, ester production was modeled because methyl esters are the predominant product of commerce, because methanol is considerably cheaper than ethanol, and due to the greater ease of downstream recovery of unreacted alcohol (Zhou and Boocock, 2003). Ethanol has the advantage that it is renewable. It can be produced from agricultural renewable resources, thereby attaining total independence from petroleum-based alcohols (Encinar et al., 2007). Most of the world's methanol is being produced using natural gas as a feedstock, however, the ability to produce methanol from renewable biomass resources is growing in interest. Methanol was the alcohol of choice: Methanol (Analytical) ElNasr Pharmaceutical Chemicals Co. (ADWIC) Mwt. 32.04 assay $99.8 \%$. Both $\mathrm{KOH}$ and $\mathrm{NaOH}$ were used in that study: $\mathrm{NaOH}$ pellets purified SISCO Research Laboratories PVT Ltd-India KOH pellets purified Thann-Fransu. One of the most important variables affecting the yield of ester is the molar ratio of alcohol to triglyceride. The stoichiometric ratio for transesterification requires three moles of alcohol and one mole of triglyceride to yield three moles of fatty acid alkyl esters and one mole of glycerol. However, transesterification is an equilibrium reaction in which a large excess of alcohol is required to drive the reaction to the right. For maximum conversion to the ester, a molar ratio of 6:1 was mostly used (Encinar et al., 2005; Meka et al., 2007). In this study three alcohol-to-oil molar ratios (3:1, 6:1 and 9:1) were applied.

Among the most commonly used alkaline catalysts in the biodiesel industry are potassium hydroxide $(\mathrm{KOH})$ and sodium hydroxide $(\mathrm{NaOH})$ flakes which are inexpensive, easy to handle in transportation and storage, and are preferred by small producers. Alkyl oxide solutions of sodium methoxide or potassium methoxide in methanol, which are now commercially available, are the preferred catalysts for large continuous-flow production processes (Singh et al., 2006). Potassium or sodium methoxide solution was prepared freshly by mixing a predetermined amount of methanol ( $20 \%$ by weight of oil) with $\mathrm{KOH}$ or $\mathrm{NAOH}$ ( $1.0 \%$ by weight of oil) in a container. Two catalyst loadings $(0.5 \%$ and $1.0 \% \mathrm{KOH} \mathrm{wt} / \mathrm{wt}$.) were applied.

The reaction was carried out for $1-3 \mathrm{~h}$. under reflux at $60-70{ }^{\circ} \mathrm{C}$. Stirring was started with the reaction at the moment of adding potassium or sodium methoxide solution. After the predetermined reaction time, the mixture was carefully transferred to a separating funnel and allowed to stand there overnight. The lower layer (glycerol, methanol and most of the catalysts) was drained out. The upper layer (methyl esters, some methanol and traces of the catalyst) was then cleaned thoroughly by washing with warm $\left(50^{\circ} \mathrm{C}\right)$ de-ionized water. The methyl ester was then dried with anhydrous $\mathrm{Na}_{2} \mathrm{SO}_{4}$. Several examples of microwave irradiated transesterification methods have been reported using adapted domestic ovens to use them as flow systems (Saiffudin et al., 2004) or batch laboratory ovens (Mazzocchia et al., 2004) but only moderate conversions were obtained. A more recent study used homogeneous catalysis, both in a batch and in a flow system (Hernando et al., 2007). Leadbeater and Stencel reported the use of microwave heating as a fast, simple way to prepare biodiesel in a batch mode (Leadbeater and Stencel, 2006). This was followed by a continuousflow approach allowing for the reaction to be run under atmospheric conditions and performed at flow rates of up to $7.2 \mathrm{~L} / \mathrm{min}$ using a $4 \mathrm{~L}$ reaction vessel. (Barnard et al., 2007). In this study, a scientific microwave with advanced vessel technology was used. This allowed 
fast vessel heating with homogeneous microwave distribution throughout the cavity. The oven used is Start S (Milestone) Milestone Inc. (U.S.A.) Normal pressure glass reactor complete with $500 \mathrm{~mL}$ flask and reflux condenser. The oven is supplied with a color touch screen controller which enables creation, store and use of time-vs.-temperature or time-vs.-power reaction profiles. The output microwave power is adjustable up to 1200 watts, controlled via microprocessor. The optimum parametric conditions obtained from the conventional technique were applied again using microwave irradiation in order to compare both systems. The temperature was adjusted to $65^{\circ} \mathrm{C}$, a methanol/oil molar ratio of 6:1 was employed, and potassium hydroxide ( $1 \%$ ) was used as a catalyst. The oil was preheated to the desired temperature of $65^{\circ} \mathrm{C}$ using the microwave unit. The alcohol-catalyst mixture was then fed into the flask through the condenser. The output power was adjusted to 500 watts and the mixture was irradiated under reflux applying different reaction times of 30, 60, 90, 120, 150, 180 and 240 s GC analysis was undergone for all the samples using Agilent 5975 GC/MS System Agilent Technologies (U.S.A.). The engine used to investigate the performance is a Diesel Perkins Engine (Perkins Engines Company Limited, England), 4-cylinder, 4-stroke cycle, $41.5 \mathrm{~kW}$ power. The flue gas analyzer used to test the exhaust emissions is Testo 350 (Testo AG, Lenzkirch, Germany).

\section{RESULTS AND DISCUSSION}

The results obtained by applying the conventional technique was discussed in detail in a previous study by the authors (Refaat et al., 2008). From the results, it was clear that the produced biodiesel fuel was within the recommended standards of the biodiesel fuel with $96.15 \%$ yield. Biodiesel produced from waste vegetable oil was comparable in composition, similar in calorific value to biodiesel produced from refined sunflower oil. Application of radio frequency microwave energy enhances the reaction rate for the conversion of triglycerides to biodiesel, and drives the reaction equilibrium toward the production of biodiesel. $100 \%$ biodiesel yield was obtained by applying microwave irradiation for two min. compared to one $\mathrm{h}$. with the conventional technique. The static separation time was $30 \mathrm{~min}$. compared to $8 \mathrm{~h}$. with the conventional technique. Application of radio frequency microwave energy further improves product recovery in the separation of the biodiesel product from alcohol and glycerin in the reaction mixture. The results achieved by applying microwave irradiation were compared to those obtained by applying the conventional technique (Table 1). From these results it is evident that using microwave irradiation reduces the reaction time by about $97 \%$ and the separation time by about $94 \%$.

Table 1: Comparison between microwave irradiation and the conventional technique

\begin{tabular}{llll}
\hline System & $\begin{array}{l}\text { Reaction time } \\
(\mathrm{min} .)\end{array}$ & $\begin{array}{l}\text { Separation time } \\
(\mathrm{min} .)\end{array}$ & $\begin{array}{l}\text { Yield } \\
(\%)\end{array}$ \\
\hline Conventional & 60 & 480 & 96 \\
Microwave & 2 & 30 & 100 \\
\hline
\end{tabular}

No substantial differences were obtained with the different origin of the oil. So, using microwave irradiation allows the use of high FFA content feed stocks, including animal fats and used cooking oils, in existing transesterification processes by promoting the removal of the fatty acid. The study also showed that the optimum reaction time for microwave-enhanced biodiesel production should be highly respected. Exceeding the optimum reaction time will lead to deterioration of both biodiesel yield and purity. These results are depicted in Fig. 1. At reaction times more than 2 min., drastic decreases in biodiesel yields were observed. The interpretation of these results requires further investigation. The most accepted interpretation is that the exceeded time favors the equilibrium in the reverse direction. Attributing the decrease in yield after exceeding the optimum time to cracking followed by oxidizing of the formed fatty acid methyl esters to aldehydes, ketones and lower chained organic fractions could be excluded because the GC results do not show peaks of oxygenated compounds. Several studies (Ozgunay et al., 2007; Usta, 2005; Pramanik, 2003; Dorado et al., 2003b) which have previously carried out performance tests with biodiesel fuels produced from different resources, stated that biodiesel shows slightly lower performance values in comparison with petroleum diesel fuel performance. Kegl reported that because of the lower heating value of biodiesel fuel, the engine effective power is reduced by about $5 \%$ and the specific fuel consumption is increased by about $10 \%$, whereas the thermal efficiency is practically the same for both fuels. The temperatures of exhaust gases as well as the in-cylinder pressures were lower than those obtained with petroleum diesel (Kegl, 2006). Brake specific energy consumption (bsec) or brake thermal efficiency (the inverse of bsec) are more 
adequate parameters than bsfc for comparing fuels and for evaluating the engine capability to be fuelled with biodiesel and biodiesel blends (Cardone et al., 2002). Agarwal observed significant improvement in engine performance and emission characteristics for the biodiesel-fuelled engine compared to dieselfuelled engine. Thermal efficiency of the engine improved, brake specific energy consumption reduced and a considerable reduction in the exhaust smoke opacity was observed (Agarwal and Agarwal, 2007). The results of the performance tests carried out in this study with petroleum diesel fuel and biodiesel are discussed below and presented comparatively in Fig. 2 where the relative changes in parameters with respect to petroleum diesel are shown. The difference in performance between microwave-enhanced biodiesel and petroleum diesel was not statistically significant. Fig. 3 reveals a slight increase in specific fuel consumption (SFC) detected with biodiesel. Fig. 4 shows that no significant differences were observed in brake thermal efficiency. Combustion efficiency remained constant using either microwave-enhanced biodiesel or diesel fuel.

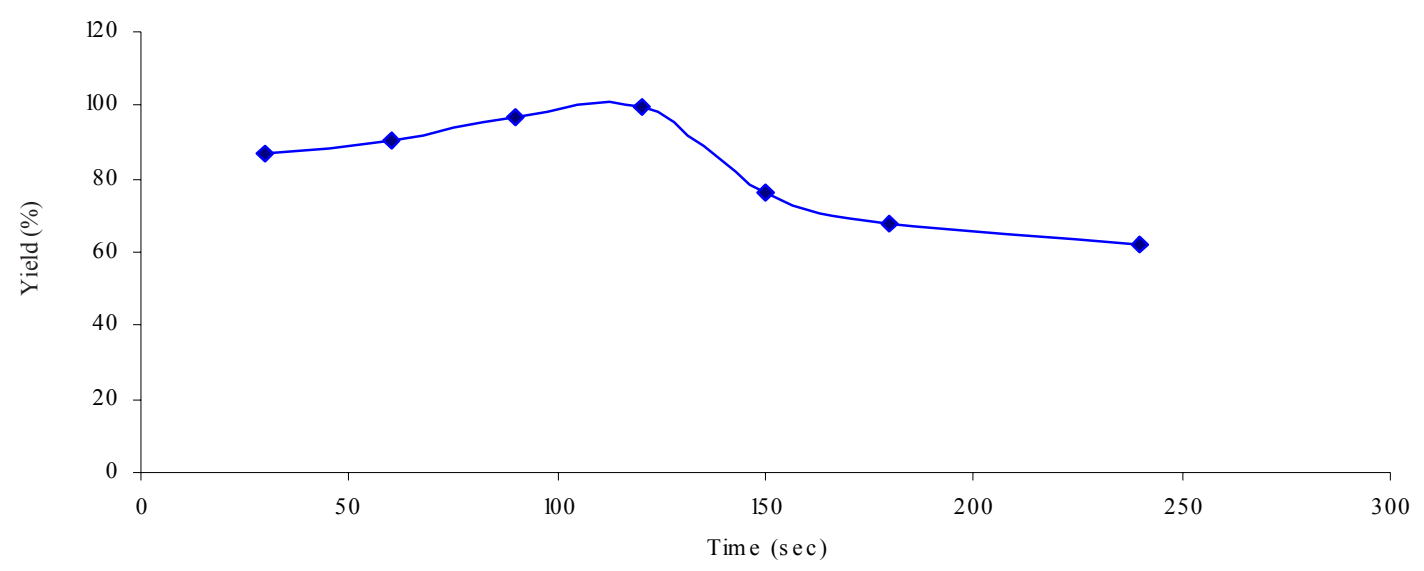

Fig. 1: Effect of reaction time on yield

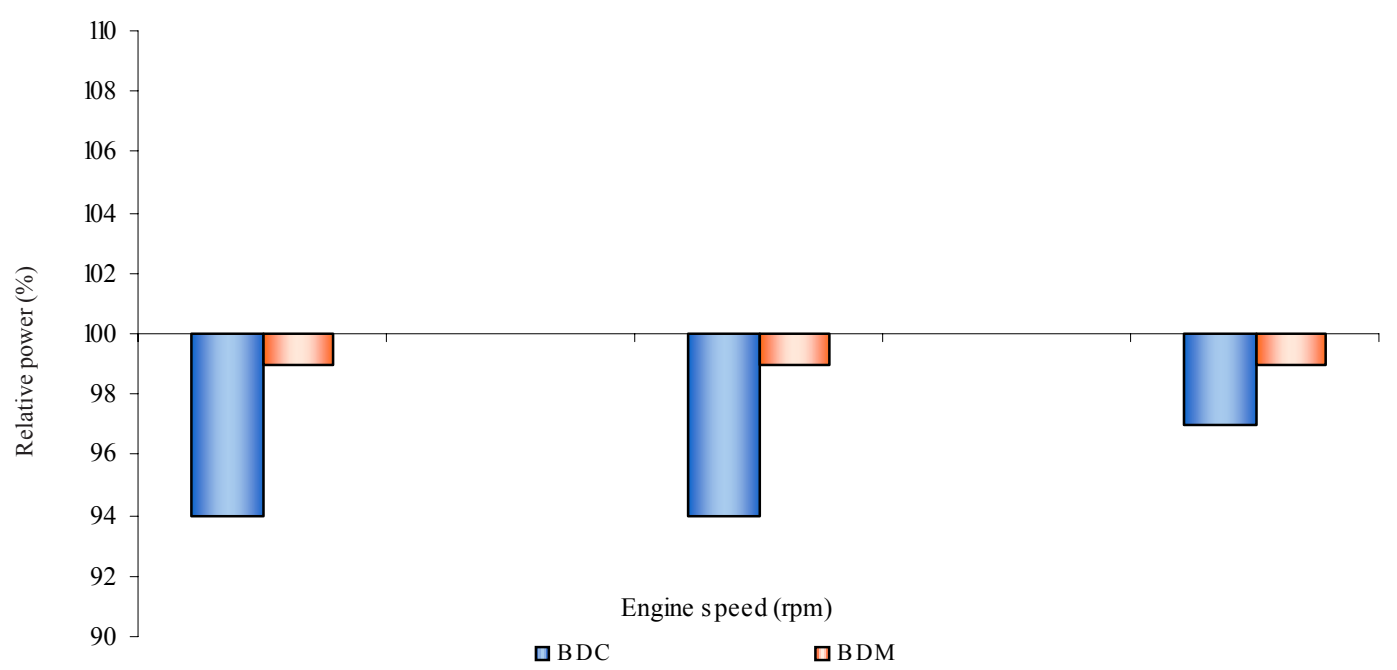

Fig. 2: Relative performance of biodiesel compared to petroleum diesel (baseline) at different engine speeds 


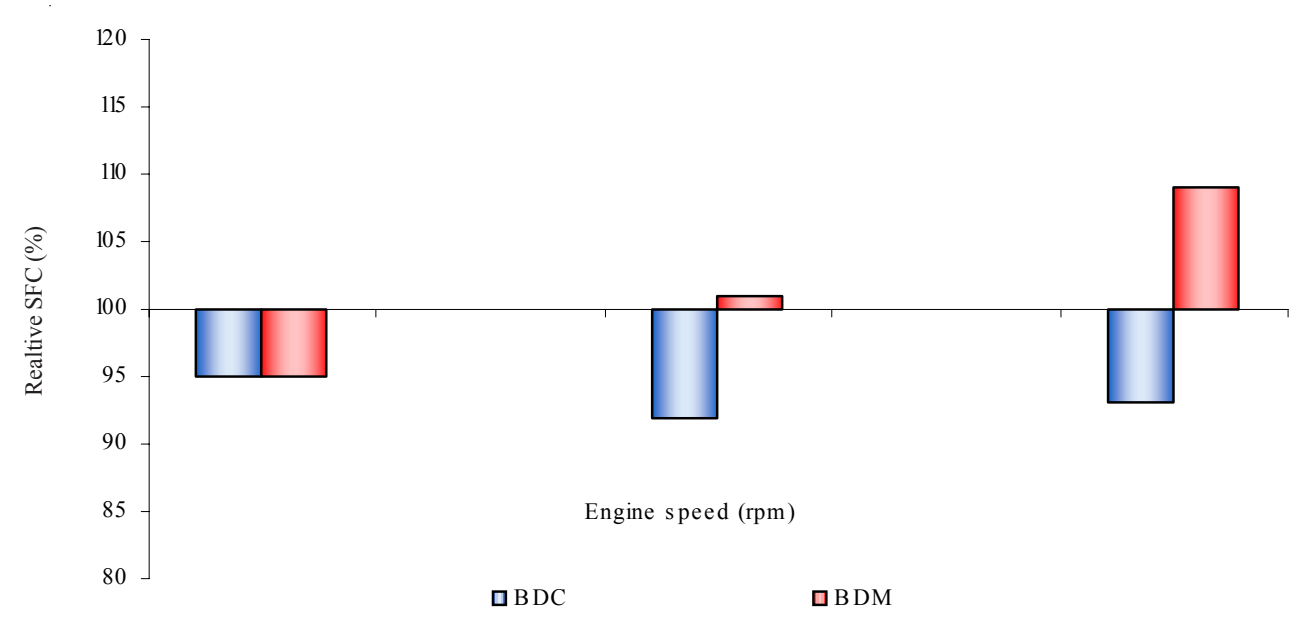

Fig. 3: Relative SFC of biodiesel compared to petroleum diesel (baseline) at different engine speeds

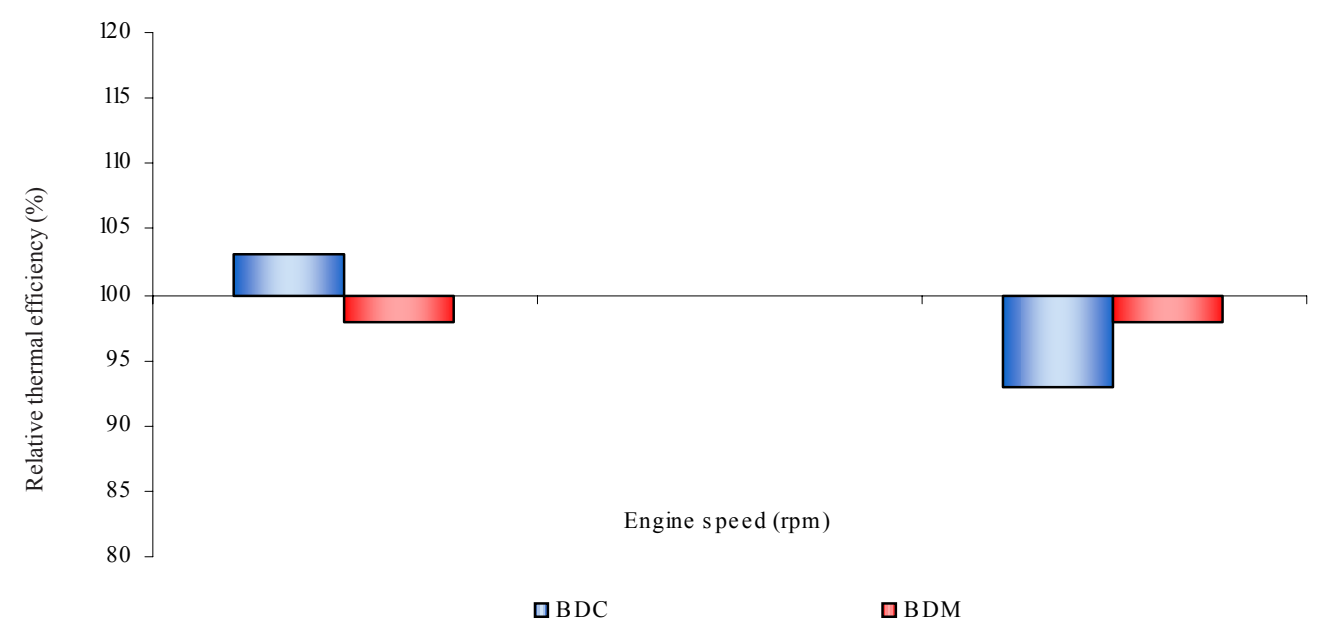

Fig. 4: Relative Thermal efficiency of biodiesel compared to petroleum diesel (baseline) at different engine speeds

Compared to mineral diesel, biodiesel generally causes a decrease of unburned $\mathrm{HC}, \mathrm{CO}$ and PM emissions and an increase of $\mathrm{NO}_{\mathrm{x}}$ emission. The actual results, however, vary significantly in dependence on the used fuel, employed engine, and engine operating regimes (Kegl, 2006). Ramadhas et al., have found a significant decline in $\mathrm{CO}$ emission values with increasing ratios of the biodiesel to petro-diesel (Ramadhas et al., 2005). Results obtained by Murillo et $a l$. revealed that the use of biodiesel resulted in lower emissions of $\mathrm{CO}$ (up to $12 \%$ ) with an increase in emissions of $\mathrm{NO}_{\mathrm{x}}$ (up to $20 \%$, except in one case which presented a slight reduction) (Murillo et al., 2007). Kegl indicated that, by using biodiesel, harmful emissions $\left(\mathrm{NO}_{\mathrm{x}}, \mathrm{CO}\right.$, smoke and $\left.\mathrm{HC}\right)$ can be reduced to some extent by adjusting the injection pump timing properly (Kegl, 2006). In this study, evaluation of the data relating to emission values indicate that, despite the small increase in $\mathrm{NO}_{x}$ emissions, decreases in $\mathrm{CO}, \mathrm{NO}$ and $\mathrm{NO}_{2}$ emissions as a result of firing biodiesel were found to be statistically important compared to the emissions when burning diesel (Fig. 5). Although the results of the power tests of biodiesel are similar to petroleum diesel fuel performance values, a slight increase in 


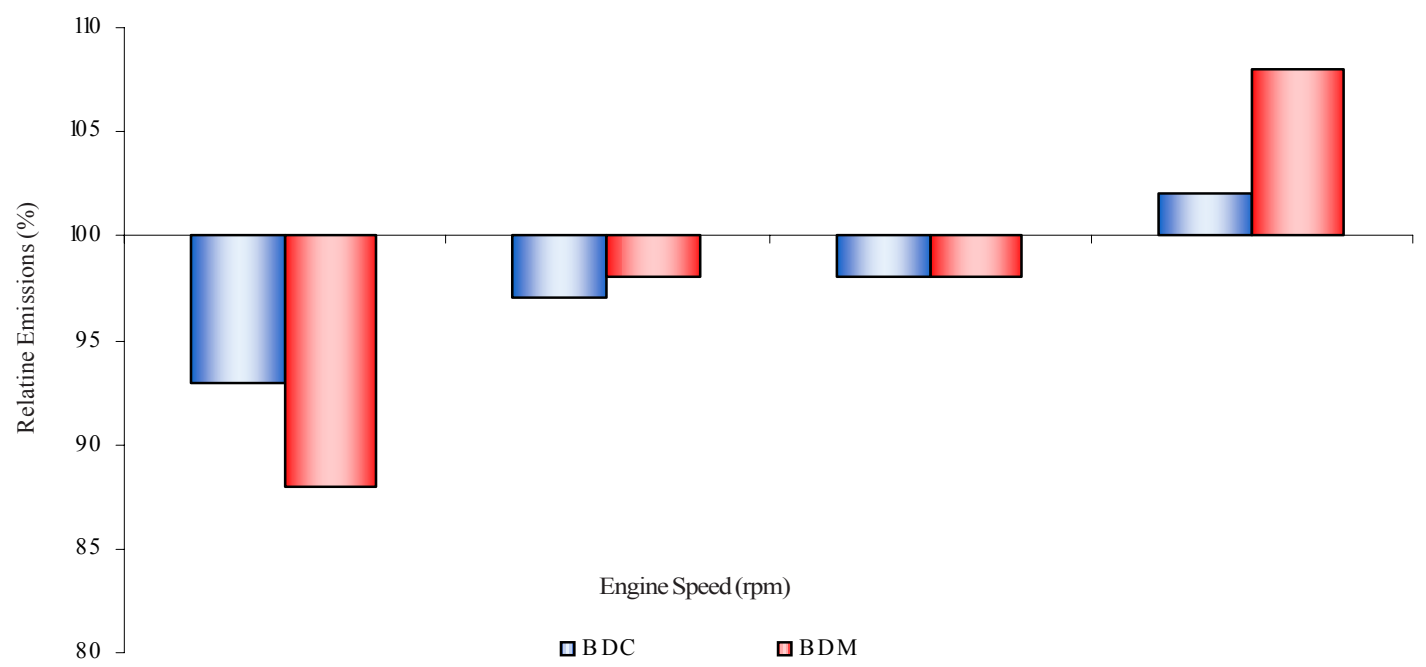

Fig. 5: Relative exhaust emissions of biodiesel compared to petroleum diesel (baseline)

SFC was detected with biodiesel. The slight increase in brake-specific fuel consumption (lower than $8 \%$ ) observed with biodiesel may be tolerated due to the exhaust emission benefits.

\section{REFERENCES}

Agarwal, D.; Agarwal, A. K., (2007). Performance and emissions characteristics of Jatropha oil (preheated and blends) in a direct injection compression ignition engine. Appl. Therm. Eng., 27 (13), 2314-2323.

Barnard, T. M.; Leadbeater, N. E.; Boucher, M. B.; Stencel, L. M.; Wilhite, B. A., (2007). Continuous-Flow preparation of biodiesel using microwave heating. Energ. Fuel., 21 (3), 17771781.

Cardone, M.; Prati, M. V.; Rocco, V.; Seggiani, M.; Senatore, A.; Vitolo, S., (2002). Brassica carinata as an alternative oil crop for the production of biodiesel in Italy: Engine performance and regulated and unregulated exhaust emissions. Environ. Sci. Tech., 36 (21), 4656-4662.

Dorado, M. P.; Ballesteros, E.; Arnal, J. M.; Gomez, J.; Lopez, F. J., (2003a). Exhaust emissions from a Diesel engine fueled with transesterified waste olive oil. Fuel, 82 (11), 13111315.

Dorado, M. P.; Ballesteros, E.; Arnal, J. M.; Gomez, J.; Lopez, F. J., (2003b). Testing waste olive oil methyl ester as a fuel in a ddiesel engine. Energ. Fuel., 17 (6), 1560-1565.

Encinar, J. M.; Juan, F.; Gonzalez, J. F.; Rodriguez-Reinares, A., (2005). Biodiesel from used frying oil: Variables affecting the yields and characteristics of the biodiesel. Ind. Eng. Chem. Res., 44 (15), 5491-5499.

Encinar, J. M.; Juan, F.; Gonzalez, J. F.; Rodriguez-Reinares, A., (2007). Ethanolysis of used frying oils: Biodiesel preparation and characterization. Fuel Process. Tech., 88 (5), 513-522.
Fini, A.; Breccia, A., (1999). Chemistry by microwaves. Pure Appl. Chem., 71 (4), 573-579.

Hernando, J.; Leton, P.; Matia, M. P.; J. L. Novella, J. L.; Alvarez-Builla J., (2007). Biodiesel and FAME synthesis assisted by microwaves: Homogeneous batch and flow processes. Fuel, 86 (10-11), 1641-1644.

Kegl, B., (2006). Experimental investigation of optimal timing of the diesel engine injection pump using biodiesel fuel. Energ. Fuel., 20 (4), 1460-1470.

Kegl, B., (2008). Effects of biodiesel on emissions of a bus diesel engine. Bioresource Tech., 99 (4), 863-873.

Koopmans, C.; Iannelli, M.; Kerep, P.; Klink, M.; Schmitz, S.; Sinnwell, S.; Ritter, H., (2006). Microwave-assisted polymer chemistry: Heck-reaction, transesterification, BaeyerVilliger oxidation, oxazoline polymerization, acrylamides, and porous materials. Tetrahedron, 62 (19), 4709-4714.

Lapuerta, M.; Rodriguez-Fernandez, J.; Agudelo, J. R., (2008). Diesel particulate emissions from used cooking oil biodiesel. Bioresource Tech., 99 (4), 731-740.

Leadbeater, N. E.; Stencel, L. M., (2006). Fast, Easy preparation of biodiesel using microwave heating. Energ. Fuel., 20 (5), 2281-2283.

Lidstrom, P.; Tierney, J.; Wathey, B.; Westman, J., (2001). Microwave assisted organic synthesis-a review. Tetrahedron, 57 (45), 9225-9283.

Ma, F.; Hanna, M. A., (1999). Biodiesel production: A review. Bioresour. Tech., 70 (1), 1-15.

Mazzocchia, C.; Modica, G.; Nannicini, R.; Kaddouri, A., (2004). Fatty acid methyl esters synthesis from triglycerides over heterogeneous catalysts in the presence of microwaves. Comptes Rendus Chimie (CR ACAD SCI II C), 7 (6-7), 601605.

Meka, P. K; Tripathi, V.; Singh, R. P., (2007). Synthesis of biodiesel fuel from safflower oil using various reaction parameters. J. Oleo Sci., 56 (1), 9-12. 
Murillo, S.; Miguez, J. L.; Porteiro, J.; Granada, E.; Moran, J. C., (2007). Performance and exhaust emissions in the use of biodiesel in outboard diesel engines. Fuel, 86 (12-13), 1765-1771.

Ozgunay, H.; Colak, S.; Zengin, G.; Sari, O.; Sarikahya, H.; Yuceer, L., (2007). Performance and emission study of biodiesel from leather industry pre-fleshings. Waste Manag., 27 (12), 1897-1901.

Pramanik, K. (2003). Properties and use of jatropha curcas oil and diesel fuel blends in compression ignition engine. Renew. Energ., 28 (2), 239-248.

Ramadhas, A. S., Muraleedharan, C., Jayaraj, S., (2005). Performance and emission evaluation of a diesel engine fueled with methyl esthers of rubber seed oil. Renew. Energ., 30 (12), 1789-1800.

Refaat, A. A.; Attia, N. K.; , Sibak, H. A.; El Sheltawy, S. T.; ElDiwani, G. I., (2008). Production Optimization and Quality Assessment of Biodiesel from Waste Vegetable Oil. Int. J. Environ. Sci. Tech., 5 (1), 75-82.

Saifuddin, N.; Chua, K. H., (2004). Production of ethyl ester (Biodiesel) from used Frying oil: Optimization of transesterification process using microwave irradiation. Malaysian J. Chem, 6 (1), 77- 82.

Schuchardt, U.; Serchelia, R.; Vargas, R. M., (1998). Transesterification of vegetable oils: A review. J. Brazil. Chem. Soc., 9 (1), 199-210.

Singh, A. B. H.; Thompson, J.; Van Gerpen, J., (2006). Process optimization of biodiesel production using different alkaline catalysts. Appl. Eng. Agric., 22 (4), 597-600.

Tat, M. E.; Van Gerpen, J. H.; Wang, P. S., (2007). Fuel property effects on injection timing, ignition timing, and oxides of nitrogen emissions from biodiesel-fueled engines. Am. Soc. Agricultural Eng., 50 (4), 1123-1128.

Usta, N., (2005). Use of tobacco seed oil methyl ester in a turbocharged indirect injection diesel engine. Biomass Bioenerg., 28 (1), 77-86.

Van Gerpen, J., (2005). Biodiesel processing and production. Fuel Process. Tech., 86 (10), 1097-1107.

Varma, R. S., (2001). Solvent-free accelerated organic syntheses using microwaves. Pure Appl. Chem., 73 (1), 193-198.

Zhou, W.; Boocock, D. G. V., (2003). Ethyl esters from the single-phase base-catalyzed ethanolysis of vegetable oils. J. Am. Oil Chem. Soc., 80 (4), 367-371.

\section{AUTHOR (S) BIOSKETCHES}

Refaat, A. A., Teaching assistant, Department of Chemical Engineering, Faculty of Engineering, Cairo University, Cairo,Egypt.Email: aarefaat@hotmail.com

EI Sheltawy, S. T., Professor of Chemical Technology and Environmental Engineering, Faculty of Engineering, Cairo University and Former Director of Center for Environmental Research and Studies (CERS), Cairo University, Cairo, Egypt. Email: chakinaz@hotmail.com

Sadek, K. U., Professor of Organic Chemistry, Faculty of Science, Menia University, Cairo, Egypt. Email:kusadek@yahoo.com.

\section{This article should be referenced as follows:}

Refaat, A. A.; El Sheltawy, S. T.; Sadek, K. U., (2008). Optimum reaction time, performance and exhaust emissions of biodiesel produced by microwave irradiation. Int. J. Environ. Sci. Tech., 5 (3), 315-322. 